\title{
Pneumoproteinaemia: a new perspective in the assessment of lung disorders
}

\author{
C. Hermans, A. Bernard
}

\begin{abstract}
Pneumoproteinaemia: a new perspective in the assessment of lung disorders. C. Hermans, A. Bernard. C)ERS Journals Ltd 1998.

ABSTRACT: Here we make the hypothesis that the determination of the concentration of lung specific secretory proteins in serum or pneumoproteinaemia could be used in the evaluation of lung disorders with a similar utility as proteinuria in kidney diseases involving the glomeruli. Human and experimental data indicate that comparable structural and functional features govern the passage of proteins across the lung epithelium/blood barrier and the glomerular filter. The concentrations in serum of some lung-specific secretory proteins, such as the bronchiolar Clara cell $16 \mathrm{kDa}$ protein (CC16) and alveolar surfactant-associated proteins A and B (SP-A and SP-B, respectively), might be used to assess the integrity of the bronchoalveolar/blood barrier known to be disrupted in many lung disorders. In addition, if this barrier is intact or slightly compromised, these proteins might serve as peripheral markers to detect changes in secretory epithelial cells in the lung.

Eur Respir J 1998; 11: 801-803.
\end{abstract}

Unit of Industrial Toxicology and Occupational Medicine, Faculty of Medicine, Catholic University of Louvain, Brussels Belgium.

Correspondence: C. Hermans, Unit of Industrial Toxicology and Occupational Medicine, Faculty of Medicine, Catholic University of Louvain, Clos Chapelle-auxChamps, 3054, 1200 Brussels, Belgium. Fax: 3227643228

Keywords: Bronchoalveolar/blood barrier, clara cell protein (CC10-CC16), lung epithelial cell, lung marker, pneumoprotein, surfactant-associated protein (SP-A, SP-B) Received October 81997

Accepted after revision January 311998
The glomerular and alveolar capillary walls share several features in their structure and function. Both consist of endothelial and epithelial layers resting on their respective basal membrane. A basic common requirement for an appropriate functioning of these barriers is that they should allow a free diffusion and/or filtration of small molecules (solutes and gases) but efficiently retain larger plasma proteins. The functional capacity of these barriers mainly depends on their available exchange/filtration surface area which can be evaluated by the diffusion capacity of the lung for carbon monoxide (DL,CO) and the glomerular filtration rate (GFR) for the kidney.

Retention of plasma proteins at the level of the kidney is achieved by the glomerular filter whose polyanionic and porous properties almost completely hinder the filtration of negatively-charged proteins the size of albumin or larger. The selectivity of this filtration process is also dependent upon the glomerular haemodynamics i.e., the GFR and its determinants. By contrast, the glomerulus allows a free filtration of small molecules including the low molecular weight $(\mathrm{LMW})$ proteins $(<40 \mathrm{kDa})$ which are reabsorbed and catabolized by the proximal tubule. Loss of glomerular permselectivity results in an increased excretion of albumin and other high molecular weight proteins (glomerular proteinuria), which is an important hallmark of glomerular diseases, whereas impairment of tubular funtion is associated with an increased excretion of LMW proteins (tubular proteinuria) [1]. With respect to the lung, there is increasing evidence that, as in the kidney, the transepithelial passage of proteins is governed by steric, electrostatic and haemodynamic factors. Human and animal studies have indeed shown that the ability of proteins and tracers to move across the lung epithelium/blood barrier is inversely proportional to their molecular size and influenced by their shape $[2,3,4]$. This was demonstrated not only for the penetration of plasma proteins into the lung but also for the clearance of proteins and tracers from the alveolar spaces [4]. In the lung as opposed to the kidney, the flux of proteins across the epithelial barrier is however bidirectional. The predominant route of this passage appears to be paracellular via tight junctions between epithelial cells. Transcellular transport has been reported but appears to be of minor importance [4]. As for the kidney, heteroporous models have been proposed for the lung epithelium/blood barrier with a predominant population of small por-es and a small fraction of much larger pores. There is no general agreement about the exact permeability of this barrier and pore-size estimates vary between $0.5-2.5 \mathrm{~nm}$ for the small pores and up to $400 \mathrm{~nm}$ for the larger ones [2, $5,6]$. In addition to size-selective properties, polyanionic proteoglycans are present on the capillary and epithelial basal membranes as well as the interstitium, which generate an electric field repelling negatively-charged macromolecules $[7,8]$. The leakage of proteins across this barrier is probably also influenced by haemodynamic factors among which is hydrostatic pressure on both sides.

Increased permeability of the alveolar epithelial barrier is one of the main consequences of many lung disorders and results in the accumulation of varying quantities of oedema within the alveoli and the lung interstitium. Altered haemodynamics and loss of size-selectivity appear to be responsible for this accumulation, most likely through the paracellular route. Whether a loss of the charge-selectivity is also present and exacerbates this oedematous process remains to be established but this is quite conceivable by analogy with the glomerular barrier. Experimental studies 
have shown that the passage of different-sized marker molecules from the lower respiratory tract into the bloodstream also increases during inflammatory conditions and correlates with the severity of the lung injury $[9,10]$. The main route of clearance for lung proteins leaking into the interstitial space is via the bloodstream; lymphatic drainage accounting for about $25 \%$ [4]. This increase in bidirectional permeability is presently estimated by the measurement of plasma proteins in lung lavage and/or aspiration fluid or on the basis of the clearance of tracer molecules introduced into the respiratory tract $[11,12]$.

Here we hypothesize that the permeability of the alveolar barrier might be evaluated less invasively from the other side by measuring in the plasma lung-specific proteins originating from the lumen of the respiratory tract. We propose the terms pneumoproteins and pneumoproteinaemia to refer to these proteins and their occurrence in plasma. Such a typical pneumoprotein detectable in serum is the $16 \mathrm{kDa}$ Clara cell protein (CC16) secreted along the bronchial tree by nonciliated Clara cells [13]. Another pneumoprotein is surfactant-associated protein A (SP-A), a 28-35 kDa protein mainly secreted by alveolar type II cells, occurring in the respiratory tract and serum in monomeric and various oligomeric forms $[14,15]$. Similar findings have been made with the $\sim 18 \mathrm{kDa}$ surfactantassociated protein B (SP-B), secreted by both alveolar and bronchiolar cells [16].

The exact mechanism by which these proteins enter into plasma and the exact sites of their passage remain to be determined. The most plausible explanation is passive diffusion through the bronchoalveolar/blood barrier. The driving force for this movement is most likely provided by the huge concentration gradient between the epithelial lining fluid and plasma documented for some of these pneumoproteins. For instance, in the case of $\mathrm{CC} 16$, values in the bronchoalveolar lining fluid exceed those in serum by more than three orders of magnitude (fig. 1) [17-19]. In view of the sieving properties of the alveolar barrier, one might assume that small pneumoproteins like CC16 (molecular radius $\sim 1.9 \mathrm{~nm}$ ) move with little hindrance whereas the passage of larger pneumoproteins such as oligomeric

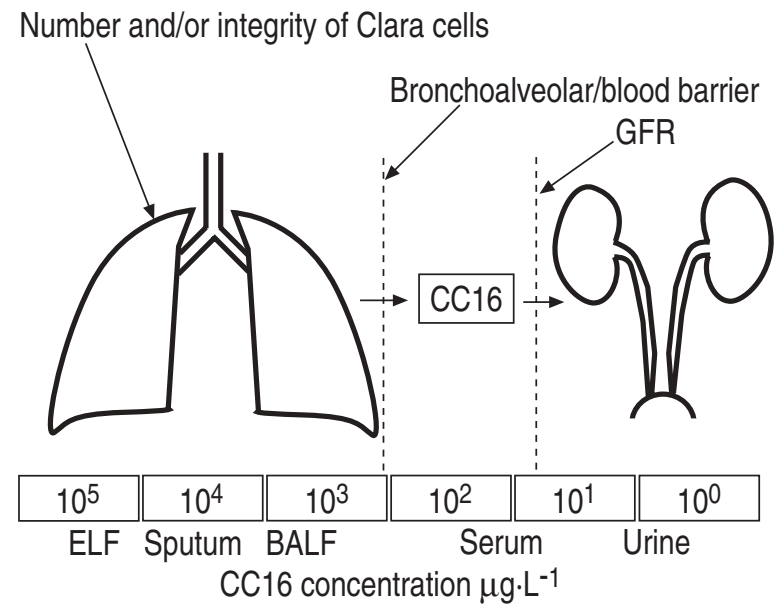

Fig. 1. - Schematic representation of the passage of $16 \mathrm{kDa}$ Clara cell protein from the lung into the blood followed by its renal elimination. Also indicated are the factors likely to influence the concentration of CC16 in serum. The scale is based on human data [17-19]. ELF: epithelial lining fluid; BALF: bronchoalveolar lavage fluid; GFR: glomerular filtration rate.
SP-A (molecular radius $\sim 11 \mathrm{~nm}$ ) is much more restricted. The hypothesis of a diffusional exchange for these proteins between the respiratory tract and the bloodstream is supported by the significant correlation between CC16 concentrations in serum and bronchoalveolar lavage fluid (BALF) of healthy subjects $[17,18]$. Like other LMW proteins, plasma CC16 is rapidly eliminated by the glomerular filtration-tubular reabsorption route and therefore increases as the GFR declines (fig. 1). However, the exact route by which the surfactant-associated proteins are cleared from the circulation has not yet been clearly determined.

The concept that lung proteins are transferred into plasma by passive diffusion across a permselective barrier leads to two potential applications. First, these proteins might be used to assess the integrity of the barrier which may be compromised in a number of disorders. An increase in serum CC16 has recently been reported in patients with interstitial lung disorders such as pulmonary fibrosis and sarcoidosis and also in subjects exposed to lung irritants such as firesmoke [20-22]. In rat, a marked increase in serum CC16 has been found following lung injury and inflammatory changes induced by different pneumotoxicants such as ozone and lipopolysarcharide (LPS) (unpublished data). In all these circumstances, an increased protein leakage across the bronchoalveolar/blood barrier was present as evidenced by the elevated levels of albumin in BALF. These findings support the hypothesis that the elevation of $\mathrm{CC} 16$ in these disorders results from an increased leakage through the bronchoalveolar/blood barrier independently of variations in its synthesis in the lung. Very interestingly, increased SP-A levels have also been observed in serum of patients with pulmonary fibrosis and adult respiratory distress syndrome (ARDS) [15, 23]. In the latter, the augmentation of SP-A was negatively correlated with indices of arterial oxygenation, an inverse relation which is reminiscent of that between proteinuria and GFR frequently seen in patients with advanced renal failure [15]. We therefore speculate that the pathophysiological mechanisms of proteinuria which have been extensively studied in health and disease might be, to a large extent, applicable to pneumoproteinaemia. Second, when the bronchoalveolar/blood barrier is intact or slightly impaired, measurement of lung-specific proteins in serum could be used to evaluate the changes in number and/or integrity of lung epithelial cells. This is supported by the decrease of CC16 in the serum of smokers, a condition where the number of Clara cells is markedly decreased as demonstrated by histological and immunohistochemical studies $[18,24-26]$. We therefore speculate that, similarly to $\mathrm{CC} 16$, other exchangeable lung-specific proteins could be identified and serve to detect epithelial changes at different levels of the respiratory tract. These observations suggest that the pneumoproteinaemia might find some applications as a noninvasive indicator for evaluating and monitoring lung disorders. Further studies are however needed to better understand the pulmonary and extrapulmonary determinants of the pneumoproteinaemia and determine its significance and usefulness in comparison with current diagnostic tools.

In conclusion, if our hypothesis is confirmed, it will certainly open up new perspectives in the assessment of lung disorders and the detection of early effects caused by pneumotoxicants in the workplace and the environment. 
Acknowledgements: This work was supported by the European Union (EV4-CT96-0171) and the National Fund for Scientific Research (Belgium). C. Hermans is Research Fellow and A. Bernard Research Director of the National Fund for Scientific Research.

\section{References}

1. Bernard A, Lauwerys R. Proteinuria: changes and mechanisms in toxic nephropathies. Crit Rev Toxicol 1991; 21: 373-405.

2. Lanken PN, Hansen-Flaschen JH, Sampson PM, Pietra GG, Haselton FR, Fishman AP. Passage of uncharged dextrans from blood to lung lymph in awake sheep. $J$ Appl Physiol 1985; 59: 580-591.

3. Parker JC, Parke RE, Granger DN, Taylor AE. Vascular permeability and transvascular fluid and protein transport in the dog lung. Circ Res 1981; 48: 549-561.

4. Folkesson HG, Matthay MA, Weström BR, Kim KJ, Karlsson BW, Hastings RH. Alveolar epithelial clearance of protein (brief review). J Appl Physiol 1996; 80: 14311445.

5. Conhaim RL, Eaton A, Staub NC, Heath TD. Equivalent pore estimate for the alveolar-airway barrier in isolated dog lung. J Appl Physiol 1988; 64: 1134-1142.

6. Taylor AE, Gaar KA Jr. Estimation of equivalent pore radii of pulmonary capillary and alveolar membranes. Am J Physiol 1970; 218: 1133-1140.

7. Lai-Fook SJ, Brown LV. Effects of electric charge on hydraulic conductivity of pulmonary interstitium. J Appl Physiol 1991; 70: 1928-1932.

8. Swanson JA, Kern DF. Characterization of pulmonary endothelial charge barrier. Am J Physiol 1994; 266 (4 Pt 2): H1300-H1303.

9. Hastings RH, Grady M, Sakuma T, Matthay MA. Clearance of different-sized proteins from the alveolar space in humans and rabbits. J Appl Physiol 1992; 73: 1310-1316.

10. Folkesson HG, Weström BR, Pierzynowski SG, Karlsson BW. Lung to blood passage of different-sized molecules during lung inflammation in the rat. J Appl Physiol 1991; 71: 1106-1111.

11. Newhouse MI, Jordana M, Dolovich M. Evaluation of lung epithelial permeability. Eur J Nucl Med 1987; 13 Suppl: S58-62.

12. Staub NC, Hyde RW, Crandall E. NHLBI workshop summary. Workshop on techniques to evaluate lung alveolar-microvascular injury. Am Rev Resp Dis 1990; 141: 1071-1077.

13. Singh G, Singh J, Katyal SL, et al. Identification, cellular localization, isolation and characterization of human Clara cell specific $10 \mathrm{kDa}$ protein. J Histochem Cytochem 1988; 36: 73-80.

14. Voss T, Eistetter H, Schafer KP, Engel J. Macromolecular organization of natural and recombinant lung surfactant protein SP 28-36. Structural homology with the complement factor Clq. J Mol Biol 1988; 201: 219-227.

15. Doyle IR, Nicholas TE, Bersten AD. Serum surfactant protein-A in patients with acute cardiogenic pulmonary edema and adult respiratory distress syndrome. Am J Respir Crit Care Med 1995; 152: 307-317.

16. Doyle IR, Berstein AD, Nicholas TE. Surfactant proteinsA and -B are elevated in plasma of patients with acute respiratory failure. Am J Resp Crit Care Med 1997; 156: 1217-1229.

17. Bernard A, Marchandise FX, Depelchin S, Lauwerys R, Sibille Y. Clara cell protein in serum and bronchoalveolar lavage. Eur Resp J 1992; 5: 1231-1238.

18. Shijubo N, Itoh Y, Yamaguchi T, et al. Serum and BAL Clara cell $10 \mathrm{kDa}$ protein (CC10) levels and CC10 positive bronchiolar cells are decreased in smokers. Eur Resp J 1997; 10: 1108-1114.

19. Bernard A, Dumont X, Roels HA, et al. The molecular mass and concentration of protein 1 or Clara cell protein in biological fluids: a reappraisal. Clin Chim Acta 1993; 223: 189-191.

20. Lesur O, Bernard A, Arsalane K, et al. Clara cell protein (CC16) induces a phospholipase A2-mediated inhibition of fibroblast migration in vitro. Am J Respir Crit Care Med 1995; 152: 290-297.

21. Hermans C, Petrek M, Kolek V, Pieters Th, Lambert M, Bernard A. Serum Clara cell protein (CC16) correlates with chest radiographic abnormalities of sarcoidosis. Am J Resp Crit Care Med 1997; 155: A981.

22. Bernard A, Hermans C, Van Houte G. Transient increase of serum Clara cell protein $(\mathrm{CC} 16)$ after exposure to smoke. Occup Environ Med 1997; 54: 63-65.

23. Kuroki Y, Tsutahara S, Shijubo N, et al. Elevated levels of lung surfactant protein A in sera from patients with idiopathic pulmonary fibrosis and pulmonary alveolar proteinosis. Am Rev Resp Dis 1993; 143: 723-729.

24. Bernard A, Roels HA, Buchet JP, Lauwerys R. Decrease of serum Clara cell protein in smokers. Lancet 1992; 339: 1620 .

25. Bernard A, Roels HA, Buchet JP, Lauwerys R. Serum Clara cell protein: an indicator of bronchial cell dysfunction caused by tobacco smoke. Environ Res 1994; 66: 96104.

26. Lumsden AB, McLean A, Lamb D. Goblet and Clara cell of human distal airways, evidence for smoking induced changes in their number. Thorax 1984; 39: 844-849. 